4 Krup MA, Chatton MJ. Current medical diagnosis and treatment 1983. Los Altos: Lange Medical Publications, 1983:594.

${ }^{5}$ Mathews WB. Demyelinating disease. In: Weatherall DJ, Ledingham JGG, Warrell DA, eds. Oxford textbook of medicine. Vol 2. London: Oxford University Press, 1983:21 95-100.

${ }^{6}$ Loy TT. Treatment of cervical spondylosis: electroacupuncture versus physiotherapy. Med F Aust 1983;ii :32-4.

\section{Acetate or bicarbonate for haemodialysis?}

Early dialysis systems used bicarbonate to correct the acidosis of renal failure, and this required carbon dioxide to be bubbled continuously through the dialysis fluid to prevent a rise in $\mathrm{pH}$ and the subsequent formation of insoluble salts of calcium and magnesium. Mion et al in $1964^{1}$ showed that patients could rapidly metabolise acetate to bicarbonate, and since then acetate, which is more stable and convenient to use than bicarbonate, has become the source of buffer in haemodialysate. Recent evidence, ${ }^{2-7}$ however, suggests that some patients metabolise the acetate load more slowly than others and may develop high concentrations of acetate in the blood during dialysis. Hyperacetataemia has been linked with unpleasant symptoms ${ }^{2}$ such as nausea, malaise, and sudden hypotension ${ }^{8-11}$ as well as accelerated atherogenesis due to diversion of acetylcoenzyme A formed during acetate metabolism to lipid biosynthesis. ${ }^{12}$ These reports have coincided with the production of new dialysis systems capable of delivering bicarbonate in the dialysate. It is therefore important to examine the evidence on which the concept of so called acetate "intolerance" is based.

The normal blood acetate concentration ranges between 10 and $400 \mu \mathrm{mol} / 1(0.6 \text { and } 23.6 \mathrm{mg} /)^{4-6}{ }^{4-6-15}$ It can be measured by gas chromatography, ${ }^{413} 15$ isotachophoresis, ${ }^{10} 16$ and enzymatic methods, ${ }^{14}$ provided that the generation of acetate from glucose in the preparative stage ${ }^{15}$ is avoided. Some claims of acetate toxicity must be treated cautiously, either because blood concentrations were not actually measured ${ }^{9}{ }^{9}$ or because unsatisfactory methods were used. ${ }^{2} 1517$ During dialysis the arterial concentration of acetate remains at about $2-4 \mathrm{mmol} / 1(12-24 \mathrm{mg} 100 \mathrm{ml})$ in about three quarters of patients, though in those who metabolise acetate slowly it may increase to $15 \mathrm{mmol} / 1(89 \mathrm{mg} / 100 \mathrm{ml})$ or more. ${ }^{5}$ ? The usual concentration of acetate in the dialysate is $35 \mathrm{mmol} / 1$ $(207 \mathrm{mg} / 100 \mathrm{ml})$ and hyperacetataemia is more likely to occur if this is increased ${ }^{3}$ or if dialysers with very large surface areas $\left(>1.5 \mathrm{~m}^{2}\right)$ are used. ${ }^{3}{ }^{6}$ The maximum rate of utilisation of acetate is roughly $2-5 \mathrm{mmol} / \mathrm{min} 70 \mathrm{~kg}$, $^{18}$ and may be impaired $^{1819}$ in the presence of renal failure, diabetes, liver disease, and poor tissue perfusion. After conversion to acetylcoenzyme A most acetate is metabolised by way of the Krebs cycle, ${ }^{3}$ producing increased concentrations of some intermediates ${ }^{16}$ and organic acids, ${ }^{36}{ }^{20}$ although there is little evidence ${ }^{21}$ of enhanced lipid formation.

Haemodialysis is associated with hypotension in about a quarter of patients, which is important because it limits ultrafiltration and contributes to the morbidity of the procedure. Normally the reduction in circulating volume due to removal of fluid is compensated for by changes in peripheral resistance and cardiac output and by vascular refilling. ${ }^{22}$ In some patients, however, peripheral resistance may fail to increase, possibly because the sympathetic response to volume depletion is inhibited, or because of an increase in body temperature. ${ }^{23}$ Similarly, the production of a compensatory tachycardia may be impaired ${ }^{24}$ because of autonomic neuropathy, diminished activity of the baroreceptors, or postsynaptic unresponsiveness. Vascular refilling may be restricted if the sodium concentration in the dialysate is inappropriately low. ${ }^{25}$

It has been suggested that acetate may contribute to the hypotension associated with dialysis by causing vasodilatation $^{1022}$ and impaired myocardial contractility. ${ }^{8112627}$ Though acetate does reduce peripheral resistance, ${ }^{28}$ the effect in an individual patient is unpredictable, ${ }^{29}$ and vasodilatation is usually accompanied by an increase in cardiac output. ${ }^{22}$ The evidence for a specific "cardiodepressant" effect of acetate is open to debate. For example, the impairment of myocardial function during acetate dialysis inferred by Aizawa $e t a l^{8}$ may merely reflect a fall in peripheral resistance. In any case, these authors used indirect methods to study cardiac function, which may not be appropriate for patients having dialysis. ${ }^{22}{ }^{30}$ Kirkendol et al showed that massive bolus injections of acetate (and bicarbonate) reduced the contractile force of the myocardium, ${ }^{26}$ but the relevance of this particular observation is not clear, particularly as later work using an infusion of acetate showed the opposite effect. ${ }^{27}$ Furthermore, other clinical $^{730}$ and laboratory ${ }^{31}$ studies have shown that an infusion of acetate increases cardiac output and that acetate alone can provide a satisfactory source of energy for the mammalian heart, even under ischaemic conditions. ${ }^{32}$ Nevertheless, many workers have claimed that the incidence of hypotensive episodes is reduced if dialysate containing bicarbonate, rather than acetate, is used. ${ }^{8911} 2933$

Complex changes in acid base balance occur during haemodialysis. ${ }^{20}$ In the early stages metabolism of acetate may not keep up with the loss of bicarbonate from the patient into the dialysate so that a fall in arterial bicarbonate and $\mathrm{pH}$ may result. Influx of acetate and generation of bicarbonate continue during dialysis, and an appreciable alkalosis may develop by the end of a dialysis. These changes may be compounded by hyperventilation due to the fall in $\mathrm{pH}$, hypoventilation secondary to loss of carbon dioxide through the dialyser ${ }^{34}$ and hypoxaemia resulting from plugging of the pulmonary circulation with microthrombi consisting of leucocytes, which are caused by contact with the dialyser membrane..$^{35}$ The combined effect of these changes on blood gases and $\mathrm{pH}$ may be hard to predict, especially since there are secondary changes in the affinity of haemoglobin for oxygen. Symptoms such as fatigue and nausea have been ascribed to tissue hypoxia and may be relieved by the administration of oxygen. ${ }^{36}$ Bicarbonate dialysis prevents some of the changes, ${ }^{11} 2029$ perhaps because ventilation is maintained by the high partial pressure of carbon dioxide in the dialysate.

Instability of the circulation must therefore reflect not only the presence of the acetate ion but also changes in blood volume, acid-base balance, and autonomic dysfunction. Many of the adverse effects attributed to acetate appear only when large and highly efficient dialysers are used-generally because of the pressure to dialyse large numbers of patients in the shortest possible time. The problem of overload with acetate encountered in the United States may, therefore, be of limited interest in Britain, where dialysers with large surface areas are seldom used.

The function of the cardiovascular system during haemodialysis is attracting much attention, and the various factors which lead to vascular instability are being defined. The new bicarbonate dialysers provide a stimulus to this research and 
another treatment option in the renal unit, though they are more complicated and expensive than the standard systems. So in which patients is the extra cost and complexity justified? It seems at present that bicarbonate dialysis should be reserved for those patients with unstable circulations, whether or not associated with diabetes or liver disease, and that further work is urgently needed to define other groups of patients who may benefit. Although very ill patients with acute renal failure might be expected to be particularly sensitive to the side effects of acetate dialysis, ${ }^{11}$ the advantages of bicarbonate dialysis for this group remain to be confirmed. ${ }^{37}$

Locum Consultant Nephrologist,

Martin A Mansell

St George's and St James's Hospitals,

London SW17 0QT

Consultant Physician,

A J WING

St Thomas's Hospital,

London SE1 7EH

${ }^{1}$ Mion CM, Hegstrom RM, Boen ST, Scribner BH. Substitution of sodium acetate for sodium bicarbonate in the bath fluid for hemodialysis. Trans Am Soc Artif Intern Organs 1964;10:110-3.

2 Novello A, Kelsch RC, Easterling RE. Acetate intolerance during hemodialysis. Clin Nephrol 1976;5:29-32.

3 Tolchin N, Roberts JL, Hayashi J, Lewis EJ. Metabolic consequences of high mass-transfer hemodialysis. Kidney Int 1977;11:366-78.

${ }^{4}$ Desch G, Oules R, Mion C, Descomps B, De Paulet AC. Plasma acetate levels during hemodialysis. Clin Chim Acta 1978;85:231-41.

${ }^{5}$ Mansell MA, Nunan TO, Laker MF, Boon NA, Wing AJ. Incidence and significance of rising blood acetate levels during hemodialysis. Clin Nephrol 1979;12:22-5.

${ }^{6}$ Kaiser BA, Potter DE, Bryant RE, Vreman HJ, Weiner MW. Acid-base changes and acetate metabolism during routine and high-efficiency hemodialysis in children. Kidney Int 1981;19:70-9.

7 Mansell MA, Crowther A, Laker MF, Wing AJ. The effect of hyperacetatemia on cardiac output during regular hemodialysis. Clin Nephrol $1982 ; 18: 130-4$

${ }^{8}$ Aizawa $Y$, Ohmori $T$, Imai $K$, Nara $Y$, Matsuoka $M$, Hirazawa $Y$. Depressant action of acetate upon the human cardiovascular system. Clin Nephrol 1977;8:477-80.

${ }^{9}$ Iseki K, Onoyama K, Maeda $\mathrm{T}$, et al. Comparison of hemodynamics induced by conventional acetate hemodialysis, bicarbonate hemodialysis and ultrafiltration. Clin Nephrol 1980;14:294-8.

10 Schohn DC, Klein S, Mitsuishi Y, Jahn HA. Correlation between plasma sodium acetate concentration and systemic vascular resistances. Proc Eur Dial Transplant Assoc $1981 ; 18: 160-8$

11 Vincent JL, Vanherweghem J-L, Degaute J-P, Berré J, Dufaye P, Kahn RJ. Acetate-induced myocardial depression during hemodialysis for acute renal failure. Kidney Int $1982 ; 22: 653-7$.

12 Gonzalez FM, Pearson JE, Garbus SB, Holbert RD. On the effects of acetate during hemodialysis. Trans Am Soc Artif Intern Organs 1974; $20: 169-74$

${ }^{13}$ Laker MF, Mansell MA. Measurement of acetate in aqueous solutions and plasma by gas phase chromatography using a porous polymer stationary phase. Ann Clin Biochem 1978;15:228-32.

${ }^{14}$ Skutches CL, Holroyde CP, Myers RN, Paul P, Reichard GA. Plasma acetate turnover and oxidation. 7 Clin Invest 1979;64:708-13.

15 Kveim M, Bredesen JE. A gas chromatographic method for determination of acetate levels in body fluids. Clin Chim Acta 1979;92:27-32.

16 Yamakawa M, Yamamoto $T$, Kishimoto $T$, et al. Serum levels of acetate and TCA cycle intermediates during hemodialysis in relation to symptoms. Comparative study between hemodialysis with acetate dialysate versus bicarbonate dialysate. Nephron $1982 ; 32$ :155-61.

17 Kveim M, Nesbakken R. Utilization of exogenous acetate during hemodialysis. Trans Am Soc Artif Intern Organs 1975;21:138-43.

${ }^{18}$ Samar RE. Bicarbonate and acetate in haemodialysis. Contemporary Dialysis 1981; August:10-23.

19 Weiner MW. Acetate metabolism during hemodialysis. Artif Organs $1982 ; 6: 370-7$.

20 Ward RA, Wathen RL. Utilisation of bicarbonate for base repletion in hemodialysis. Artif Organs 1982;6:396-403.

21 Savdie E, Mahony JF, Stewart JH. Effect of acetate on serum lipids in maintenance hemodialysis. Trans Am Soc Artif Int Organs 1977;23: 385-92.

${ }^{22}$ Hampl H, Klopp $\mathrm{H}$, Wolfgruber $M$, et al. Advantages of bicarbonate hemodialysis. Artif Organs $1982 ; 6: 410-6$.

${ }^{23}$ Pizzarelli F, Sisca S, Zoccali C, et al. Blood temperature and cardiovascular stability in hemofiltration. Int 7 Artif Organs 1983;6:37-41.

24 Botey A, Gaya J, Montoliu J, et al. Postsynaptic adrenergic unresponsiveness in hypotensive hemodialysis patients. Proc Eur Dial Transplant Assoc $1981 ; 18: 586-91$
${ }^{25}$ Man NK, Di Giulio S, Zingraff J, Sausse A, Funck-Brentano JL. The role of sodium in the prevention of vascular instability during haemodialysis. Proc Eur Dial Transplant Assoc 1981;18:255-65.

${ }^{26}$ Kirkendol PL, Devia CJ, Bower JD, Holbert RD. A comparison of the cardiovascular effects of sodium acetate, sodium bicarbonate and other potential sources of fixed base in hemodialysate solutions. Trans Am Soc Artif Intern Organs 1977;23:399-405.

${ }^{27}$ Kirkendol PL, Robie NW, Gonzalez FM, Devia CJ. Cardiac and vascular effects of infused sodium acetate in dogs. Trans Am Soc Artif Int Organs $1978 ; 24: 714-8$.

${ }^{28}$ Keshaviah PR. The role of acetate in the etiology of symptomatic hypotension. Artif Organs 1982;6:378-84.

29 Pagel MD, Ahmad S, Vizzo JE, Scribner BH. Acetate and bicarbonate fluctuations and acetate intolerance during dialysis. Kidney Int 1982; 21 :513-8.

${ }^{30}$ Chen TS, Friedman HS, Del Monte M, Smith AJ. Hemodynamic changes during dialysis. Proc Clin Dial Transplant Forum 1979;9:66-71.

${ }^{31}$ Liang C-S, Lowenstein JM. Metabolic control of the circulation; effects of acetate and pyruvate. 7 Clin Invest 1978;62:1029-38.

${ }^{32}$ Hearse DJ, Stewart DA, Chain EB. Diabetes and the survival and recovery of the anoxic myocardium. $\mathcal{F}$ Mol Cell Cardiol 1975;7:397-415.

${ }^{33}$ Graefe U, Milutinovich J, Follette WC, Vizzo JE, Babb AL, Scribner BH. Less dialysis-induced morbidity and vascular instability with bicarbonate in dialysate. Ann Intern Med 1978;88:332-6.

34 Tolchin N, Roberts JL, Lewis EJ. Respiratory gas exchange by highefficiency hemodialysers. Nephron 1978;21:137-45.

35 Brubaker LH, Nolph KD. Mechanisms of recovery from neutropenia produced by hemodialysis. Blood $1971 ; 38: 623-31$.

${ }^{36}$ Ahmad S, Pagel M, Shen F, Vizzo J, Scribner BH. Effects of oxygen administration on the manifestation of acetate intolerance in dialysis patients. American fournal of Nephrology $1982 ; 2: 256-60$.

${ }^{37}$ Borges HF, Fryd DS, Rosa AA, Kjellstrand CM. Hypotension during acetate and bicarbonate dialysis in patients with acute renal failure. American fournal of Nephrology $1981 ; 1: 24-30$.

\section{Kielland or Caesar?}

The second stage of labour begins when the cervix is fully dilated and normally ends less than 45 minutes later $^{1}$ with delivery of the baby. The most common reasons for obstetric intervention are delay and fetal distress, but both may be diagnosed too readily. Arbitrary time limits have often been set on the second stage because of worries about fetal asphyxia and acidosis, ${ }^{2} 3$ but obstetricians now believe that timing should start only when the vertex appears at the introitus ${ }^{4}{ }^{5}$ or when pushing begins ${ }^{6}$ : full cervical dilatation alone does not endanger the fetus, and if it is diagnosed at routine vaginal examination the mother should not be encouraged to push until she feels the urge to do so.

The diagnosis of fetal distress in the second stage may also be difficult, because decelerations of the fetal heart rate are often seen even in normal babies, ${ }^{78}$ and the passage of meconium at this stage does not necessarily indicate asphyxia. ${ }^{9}$ Fetal acidosis is likely, however, when signs of fetal distress have already been seen in the first stage of labour or when decelerations and meconium appear together. ${ }^{9}$ Fetal blood sampling will resolve any uncertainty and should help to avoid unnecessary intervention. If fetal acidosis is confirmed early in the second stage caesarean section is preferable to a difficult forceps delivery. ${ }^{10}$

Midcavity arrest in the primigravid woman is often caused by uterine inertia, but the obstetrician may be reluctant to use oxytocin because of the possibility of cephalopelvic disproportion. Among multigravidas secondary arrest of labour may indeed be due to disproportion, but among primigravidas (whose risk of disproportion has been shown to be very low ${ }^{11}$ ) oxytocin may safely be used for the first time in the second stage and often produces descent and rotation of the head and a spontaneous or simple forceps delivery ${ }^{6}{ }^{12}$ Active management also reduces the incidence of occipitoposterior malposition. ${ }^{13}$ Application of these principles and the use of 